\title{
Kozo Sugiyama 1945 - 2011
}

Kozo Sugiyama was born in Gifu Prefecture Japan on September 17, 1945. He received his B.S., M.S., and Dr. Sci. at Nagoya University in 1969, 1971, 1974 respectively. For 23 years from 1974 he was a researcher at Fujitsu. During this time he spent a year at the International Institute for Applied Systems Analysis in Laxenburg in Austria. In the mid 1990s he served as the Director of the Information Processing Society of Japan. In 1997 he moved from Fujitsu to the newly-created Japan Advanced Institute of Science and Technology. His first position there was Professor of the School of Knowledge Science, but he soon became Director of the Center for Knowledge Science, and then Dean of the School of Knowledge Science. His last few years at JAIST were spent as a Vice President of the University.

Everyone in the Graph Drawing community knows the name Sugiyama for his famous paper "Methods for visual understanding of hierarchical system structures". The paper defines the layered method for drawing directed graphs; it is often simply called "Sugiyama's method". The paper was published as a technical report from Fujitsu Laboratories in the late 1970s, and appeared in a journal in 1981. It describes a very general framework for drawing directed graphs. This is one of the most influential papers in Graph Drawing; it has spawned many algorithms, many theorems, and many implementations; it forms the backbone of many commercial systems.

In 1992, Kozo wrote the first book on Graph Drawing, in Japanese. It was translated into English in 2002.

Kozo is also known for a number of other ground-breaking papers in Graph Drawing: on compound graph layout (predating clustered graphs), the magnetic spring model, and on the mental map problem.

However, Kozo's interests went far beyond Graph Drawing. He was passionate about finding better ways to assist the human process of knowledge creation. Indeed, his motivation for doing graph drawing research was to support the KJ Method, which is a way of creating and organizing ideas, commonly used in business in Japan. He developed a number of thinking support systems. He published papers on creating puzzles, and on technology to assist corporations in exchanging tacit knowledge. He wrote two books on Knowledge Science, the more recent one in 2008. In all his work, Kozo showed the courage and ability to address big problems.

Older members of the Graph Drawing community remember Kozo personally. He attended the first Graph Drawing conference in Rome. Many of us visited his laboratory either in Fujitsu or in JAIST, and he has visited our laboratories. He was an inspiration for us.

Kozo passed away on June 10, 2011. We have lost a valuable colleague and a good friend.

Peter Eades, Seok-Hee Hong, and Kazuo Misue, on behalf of the Graph Drawing community,

September 2011 